\title{
Five commercial enzyme linked immunosorbent assay kits for toxoplasma specific IgM antibody
}

\author{
D H M JOYNSON,* R A PAYNE,* A H BALFOUR, $\dagger$ E S PRESTAGE, $\dagger$ D G FLECK, \\ B S CHESSUM $\ddagger$ The *Swansea Public Health Laboratory, Wales, $\dagger$ Leeds Public Health Laboratory, and \\ $\ddagger$ Tooting Public Health Laboratory, London
}

SUMMARY Five commercially available enzyme linked immunosorbent assay (ELISA) kits for the detection of specific IgM against Toxoplasma gondii were evaluated in a three centre study and results compared with those of the Public Health Laboratory Service ELISA for Toxoplasma IgM (PHL IgM ELISA). Fifty selected sera were tested by all the methods (Toxo-M, Captia Toxo-M EIA, Toxo Enz M EIA, Toxonostika IgM EIA, Sopazyme Toxo IgM EIA) at the three reference centres in England and Wales and 177 routine sera by all the methods in one or other of the centres. Ten of the 50 selected sera contained autoimmune antibodies but no specific IgM and 29 had toxoplasma specific IgM detectable by the PHL IgM ELISA. The kits were assessed for their specificity and sensitivity compared with the PHL IgM ELISA, and the percentage coefficient of variation for binding to the solid phases was determined. They were also rated subjectively by the staff performing the assays and an overall impression of each kit was gained by allocating scores for several criteria.

There was quite close agreement among the results obtained with all five commercial assays and the PHL IgM ELISA, although some of the sera pre-selected as being potentially problematic showed the limitations of some of the assays.

Detection of specific IgM is of value in determining the probable stage of a Toxoplasma gondii infection, ${ }^{12}$ and several enzyme linked immunosorbent assay (ELISA) kits for this purpose are now commercially available. It is important, however, that any new assay should be compared with accepted procedures and evaluated using specimens in which a serological profile has been established. The three Public Health Laboratory (PHL) Toxoplasma Reference Centres in England and Wales have recently developed and standardised an ELISA for the detection of Toxoplasma specific IgM (PHL IgM ELISA) ${ }^{3}$ and are in a unique position to evaluate assays of this type.

Six firms were asked to participate in this evaluation by supplying production kits; five agreed.

\section{Material and methods}

A total of 50 pre-selected sera were tested in the assays at all three reference centres. They were used initially to standardise the PHL IgM ELISA and were included to assess the consistency of performance of this assay and the five commercial assays in different laboratories. Ten of these sera contained autoimmune antibodies but no specific IgM; most of the others had toxoplasma specific IgM detectable by the PHL IgM ELISA. One hundred and seventy seven sera were also Accepted for publication 19 January 1989 tested in one or other of the three reference centres. They were submitted from suspected cases of toxoplasmosis and were assigned to the study from the routine bench as they became available. They were selected to ensure an adequate volume $(>500 \mu \mathrm{l})$ and a uniform distribution of titres in the dye test. ${ }^{4}$ A serum with a value of 60-70 enzyme immunoassay units (EIU), as determined by the PHL IgM ELISA (moderate positive) was used to calculate the percentage coefficient of variation $(\% \mathrm{CV})$ of binding to the different solid phases.

The instructions for performing the assays and calculating the results were carefully followed. The wash procedures were carried out with the aid of commercial microtitre plate washers and absorbance values determined with commercial microtitre plate readers. The wash procedures and absorbance values for the Toxo-M EIA kit were carried out with the Abbott Pentawash II and Quantum Analyser. The PHL IgM ELISA was used as a standard with which the five commercial assays were compared.

\section{PHL IGM ELISA}

This assay uses flat bottomed Falcon microtest polyvinyl chloride flexible assay plates (Becton Dickenson, California, USA) as the solid phase. The wells are coated with anti-human IgM which "captures" IgM from the patient's serum. Antibody is 
detected using antigen indirectly labelled with horse radish peroxidase through a complex with monoclonal antibody to toxoplasma. This horse radish peroxidase complex is then detected using the chromogenic substrate $3,3^{\prime}, 5,5^{\prime}$-tetramethylbenzidine (TMB) to which hydrogen peroxide has been added. After stopping the reaction with sulphuric acid, absorbance values are determined spectrophotometrically at a wavelength of $450 \mathrm{~nm}\left(A_{450}\right)$. The $A_{450}$ value is proportional to the amount of IgM antibody to toxoplasma present in the sample. Patient specimen values are determined by comparison with the mean values of negative and high positive control sera. This assay has an overall incubation time of two and a half hours.

TOXO-M EIA (Abbott Laboratories, Workingham, Berkshire)

In this assay the patient's serum sample is incubated with a polystyrene bead coated with anti-human IgM. A conjugated immune complex consisting of toxoplasma antigen, rabbit antitoxoplasma IgG, and horse radish peroxidase is added to the bead. Captured horse radish peroxidase complex is then detected using $\mathrm{O}$ Phenylenediamine (OPD) containing hydrogen peroxide. After stopping the reaction with sulphuric acid absorbance values are determined spectrophotometrically at $\mathbf{A}_{492}$. Patient specimen values are compared with the low positive control as an index of the ratio of the mean absorbance of the specimen tested in duplicate, to the mean absorbance of the low positive control tested in triplicate. Specimens with an index greater than 0.5 are considered to be positive for antitoxoplasma IgM. The overall incubation time for this assay is three and a half hours. A bead washing device and reader were made available by the kit suppliers and used for the evaluation.

CA PTia toxo-M eia (Mercia Diagnostics, Guildford, Surrey)

This kit uses round bottomed polystyrene microtitre wells as the solid phase; the capture system is similar to that of the PHL IgM ELISA. After incubation of the patient's serum, toxoplasma antigen, indirectly labelled with horse radish peroxidase through a complex between biotinylated toxoplasma monoclonal antibody and horse radish peroxidase conjugated streptavidin, is added and incubated. This horse radish peroxidase complex is detected by TMB as described in the PHL IgM ELISA. Patient specimen values are compared with the mean value for a low positive control and absorbances equal to or greater than the mean low positive control are considered to be positive. The overall incubation time of this assay is two and a half hours.
TOXO ENZ M EIA (Northumbria Biologicals, Cramlington, Northumbria)

Flat bottomed polystyrene microtitre wells are used as the solid phase; the capture system is similar to that of the PHL IgM ELISA. After incubation of the patient's serum toxoplasma antigen is added and incubated. Unbound antigen is washed away and monoclonal antitoxoplasma IgG conjugated to horse radish peroxidase is added. This horse radish peroxidase complex is detected by TMB and absorbance values determined as previously described. An antigen-free control well is set up for each specimen and the absorbance value of this well is subtracted from the test well. Sera yielding corrected values of greater than the high positive control, or between the high positive control and low positive control, are considered to be positive. Values between 70 and $99 \%$ of the low positive control are considered to be doubtful positive and values below $70 \%$ of the low positive control to be negative.

\section{TOXONOSTIKA IgM EIA (Organon Teknika, Cambridge)}

The solid phase and capture system is similar to that of the Northumbria EIA. After incubation of the patient's serum a conjugated immune complex consisting of toxoplasma antigen, sheep anti-toxoplasma antibodies, and horse radish peroxidase is added. This horse radish peroxidase complex is detected by TMB and absorbance values determined as previously described. Patient specimen values are compared with the mean values of negative $(N)$, positive $(\mathrm{P})$, and calibrator $(\mathrm{C})$ control values or calculated from a calibration line. The $A_{450}$ cut off value is taken as $0.5(\mathrm{~N}+\mathrm{P})$ and a test is considered to be positive if its value is equal to or greater than this. An $A_{450}$ value below this level is considered to be negative. The overall incubation time is two and a half hours.

SOPAZYME TOXo IgM EIA (Soper-Biochem, Brussels, Belgium)

The solid phase and capture system is similar to that of the Mercia EIA. After incubation of the patient's serum toxoplasma antigen is added and incubated. Unbound antigen is washed away and a rabbit, antitoxoplasma $\mathrm{F}\left(\mathrm{ab}^{\prime}\right)_{2}$ fragment of antibody conjugated to horse radish peroxidase added. This horse radish peroxidase complex is detected with $2,2^{\prime}$-azino-di (3 ethyl benzthiazoline-6-sulphonic acid) to which hydrogen peroxide has been added, and absorbance values determined at $\mathbf{A}_{400}-\mathbf{A}_{414}$, or with dual wavelength readers using a reference filter close to $490 \mathrm{~nm}$. Patient specimen values are compared with mean values of negative, low positive control, and high positive control sera. The overall incubation time of this assay is three hours. 
Before test specimens were examined with any of the kits, the \%CV of binding to the various solid phases was calculated. A serum with a moderate titre $(60$ 70 EIU) of toxoplasma specific IgM was appropriately diluted for each kit and added to 96 wells (100 beads of the Toxo-M kit). The assays were completed and percentage CVs calculated from the absorbance values.

\section{Results}

The results obtained with the 50 pre-selected sera examined by the PHL IgM ELISA at the three reference centres clearly showed that this test was consistent and an acceptable standard against which the commercial assays could be compared. All three laboratories found the same 29 sera positive and 16 negative. Of the remaining five sera, four were recorded as equivocal by all the centres. The remaining serum was recorded as equivocal at one centre and negative at two. The majority result was taken and this serum was classified as negative for the comparative estimations.

Only three of the commercial kits had an equivocal classification for sera in their reporting instructions. As the results of the four sera classified as equivocal by the PHL IgM ELISA were either positive or equivocal with these assays, it was decided to accept either result as correct for all the assays.

All the solid phases had a percentage $\mathrm{CV}$ of $<10$ and there were only minor differences between them. A percentage $\mathrm{CV}$ of $<10$ was considered to be satisfactory. The readings obtained with the Toxo-M kit, however, were lower than expected and fell into the equivocal rather than the positive range.

\section{KIT SPECIFICITY AND SENSITIVITY}

The results were classified according to the manufacturers' instructions and the percentage specificity and sensitivity relative to the PHL IgM ELISA determined for each kit.
Table 1 Kit specificity and sensitivity of 50 pre-selected sera at three reference centres, and 177 routine sera at one or other centre, assessed relative to PHL IgM ELISA

\begin{tabular}{lcclll}
\hline & \multicolumn{2}{l}{$\%$ Specificity } & & \multicolumn{2}{l}{$\%$ Sensitivity } \\
\cline { 2 - 3 } \cline { 5 - 6 } & $\begin{array}{l}\text { Pre- } \\
\text { selected } \\
\text { sera }\end{array}$ & $\begin{array}{l}\text { Routine } \\
\text { sera }\end{array}$ & $\begin{array}{l}\text { Pre- } \\
\text { selected } \\
\text { sera }\end{array}$ & $\begin{array}{l}\text { Routine } \\
\text { sera }\end{array}$ \\
\hline Toxo-M EIA & 79 & 98 & 94 & 98 \\
*Captia Toxo-M & 93 & 97 & 91 & 92 \\
Toxo Enz M & 94 & 90 & 97 & 100 \\
*Toxonostika IgM & 100 & 98 & 79 & 81 \\
Sopazyme Toxo IgM & 83 & 95 & 94 & 88 \\
\hline
\end{tabular}

*Kits without equivocal classification.

The percentage specificity was expressed as:

Number of tests negative in both test and reference assay

$\underline{\text { Number of tests negative in both test and reference assay }} \times 100$

Number of tests negative in reference assay

The percentage sensitivity was expressed as:

Number of tests positive in both test and reference assay

Number of tests positive in reference assay

The specificity and sensitivity for the five kits, relative to the PHL IgM ELISA, are shown in table 1. The 50 pre-selected sera were tested at each of the three reference centres and the 150 results for each kit thus obtained were compared with those obtained with the PHL IgM ELISA. The comparative results of the 177 routine sera tested at one or other of the three centres are also shown in table 1 . The dye test titres of these sera ranged from $>4$ to $<2048$ and 49 had toxoplasma specific IgM detectable by the PHL IgM ELISA.

The specificity was lowest with the Toxo-M. Three sera containing rheumatoid factor, which were negative for specific IgM with the PHL IgM ELISA, gave positive results with this kit at all three centres. This problem with rheumatoid factor was further investigated using a panel of 20 sera containing

Table 2 Comparison of Toxo-M and PHL IgM ELISA with five sera containing varying amounts of rheumatoid factor and dye test antibody

\begin{tabular}{|c|c|c|c|c|c|c|}
\hline & \multirow{2}{*}{$\begin{array}{l}\text { Rheumatoid factor } \\
\text { reciprocal titre }\end{array}$} & \multirow{2}{*}{$\begin{array}{l}\text { Dye test } \\
\text { reciprocal titre }\end{array}$} & \multicolumn{2}{|c|}{ Toxo-M assay } & \multicolumn{2}{|c|}{ PHL IgM ELISA } \\
\hline & & & ${ }^{*}$ Index & Result & $A b s$ & Result \\
\hline $\begin{array}{l}1 \\
2 \\
3 \\
4 \\
5\end{array}$ & $\begin{array}{r}640 \\
1280 \\
2560 \\
10240 \\
1280\end{array}$ & $\begin{array}{r}<4 \\
<4 \\
<4 \\
8 \\
128\end{array}$ & $\begin{array}{l}0.617 \\
0.736 \\
1.538 \\
0.591 \\
0.988\end{array}$ & $\begin{array}{l}\text { positive } \\
\text { positive } \\
\text { positive } \\
\text { positive } \\
\text { positive }\end{array}$ & $\begin{array}{l}0.039 \\
0.035 \\
0.059 \\
0.073 \\
0.049\end{array}$ & $\begin{array}{l}\text { negative } \\
\text { negative } \\
\text { negative } \\
\text { negative } \\
\text { negative }\end{array}$ \\
\hline
\end{tabular}

*Positive control index 1.91 .

Cut off index 0.500 .

Negative control index $0 \cdot 181$. 
Table 3 Subjective impression of the kits

\begin{tabular}{|c|c|c|c|c|c|}
\hline & Toxo-M & Captia Toxo $M$ & Toxo Enz $M$ & Toxonostika Ig M & Sopazyme IgM \\
\hline $\begin{array}{l}1 \text { Ease of test procedure } \\
2 \text { Clarity of written instructions } \\
3 \text { Presentation and adequacy of reagents } \\
4 \text { Manner of expression of results and interpretation }\end{array}$ & $\begin{array}{r}7 \\
10 \\
10 \\
8\end{array}$ & $\begin{array}{r}10 \\
10 \\
10 \\
9\end{array}$ & $\begin{array}{l}7 \\
9 \\
9 \\
7\end{array}$ & $\begin{array}{l}8 \\
9 \\
9 \\
6\end{array}$ & $\begin{array}{l}7 \\
7 \\
6 \\
8\end{array}$ \\
\hline Total & 35 & 39 & 32 & 32 & 28 \\
\hline
\end{tabular}

rheumatoid factor and having varying dye test titres. Fifteen of the sera were negative with both the Toxo$\mathrm{M}$ and the PHL IgM ELISA; the remaining five sera were negative with the PHL IgM ELISA but positive with the Toxo-M. The serological results obtained with these sera are given in table 2 . These results show that false positive results can occur in the Toxo-M assay when sera containing rheumatoid factor are tested.

\section{SUBJECTIVE IMPRESSION OF THE KITS}

The kits were also rated subjectively for several criteria on a scale of $0-4$ by the staff who performed the assays. This was done at the three centres and scores for each criteria were accumulated, giving a range of $0-12$. The accumulated scores were interpreted as: $0-3$, poor, very difficult; 4-6, adequate but some difficulty; 7-9, good, easy; 10-12, excellent, very easy. Based on the criteria listed, the combined scores were as shown in table 3 .

\section{Discussion}

There was quite close agreement between the results obtained at the three reference centres with all five commercial assays and the PHL IgM ELISA. The 50 specimens tested at each of the three centres included sera that were pre-selected as being potentially problematic and the results with this group showed the limitations of some of the assays.

The Toxo-M kit gave false positive results in the presence of rheumatoid factor, resulting in a reduced specificity (table 2). The bead format required dedicated apparatus (available on loan) and generally was not liked by laboratory staff unused to this format. The kit instructions were easy to follow and contained a short procedural guide that was helpful. There were adequate volumes of reagents and the use of water for the wash procedure was a distinct advantage. The Quantum printout, with the results calculated, found favour with all operators.

The Captia Toxo M kit results showed close agreement with the PHL IgM ELISA but some of the sera which were equivocal in the reference test were negative in this assay. This kit did not give an equivocal range but has now included one in a more recent version of the assay. The microtitre format of six strips of $2 \times 8$ wells was useful and convenient with automatic machinery even when a full plate was not required. The relatively short incubation time of two and a half hours was also favoured. Green dye in the serum diluent was helpful in ensuring that the correct wells had been used. The tables provided for preparing various volumes of reagents were useful but a simplified procedural guide would also have been helpful. Interpretation of results was fairly easy.

The Toxo Enz $M$ assay results were in close agreement with those of the PHL IgM ELISA, although an occasional equivocal or low positive result occurred with some sera that were negative with the reference assay. The microtitre format of $8 \times 12$ wells was not convenient for automatic machinery when only a small number of tests were performed. The incubation time of 24 hours prolonged the assay and the use of a control well for all sera seemed unnecessary. The use of three different diluents added to the complexity of the test. The instructions were clear but a simple procedural guide would have been helpful. The results gave clear distinction between positive and negative and could easily be read visually. There was, however, no indication of expected absorbance values for the controls and therefore, no guidance on whether the assay was performing adequately.

The low sensitivity of the Toxonostika IgM assay was associated with negative results which occurred with sera found equivocal or positive with the reference test; no equivocal range was given for this assay. The microtitre format of $8 \times 12$ wells was not liked for the reasons already stated. The two and a half hours' incubation time was favoured and the instructions were clear, but a simplified procedural guide would have been helpful. The definition of a valid result was very clear and the assay easy to perform.

The specificity of the Sopazyme Toxo IgM assay was lowered because equivocal results occurred at one centre, with sera which were negative with the reference test. The total colour developed by the high control was low, only in the order of 0.2 absorbance units which dramatically limited the differentiation of positive and negative sera. The test could not be read visually. The instructions stated that the test could be read at a single or dual wavelength but this occasionally caused the interpretation to vary. The single batch 
of wash fluid powder limited the shelf life of the kit to four weeks unless the powder was subdivided and smaller volumes prepared.

The performance of two of the assays was considered to be unsatisfactory; the Toxo $M$ because it gave false positive results with some sera containing rheumatoid factor, and the Sopazyme Toxo IgM because of low colour development. The performance of the remaining assays was satisfactory, although the prolonged incubation time of the Toxo Enz $M$ was a disadvantage. The improved performance of some of the assays with the 177 routine sera was probably due to the larger number of sera negative for specific IgM in this group, $62 \%$ compared with $34 \%$ for the 50 preselected sera.

The three Toxoplasma Reference Laboratories have now had several years' experience with the PHL IgM ELISA. This test provides a quantitative result and the sensitivity is such that it enables specific IgM to be detected for about six months after infection in most cases. Specific IgM may persist, however, for more than a year in some patients ${ }^{5}$ and a full serological profile may be necessary to establish the approximate date of infection. This is particularly important when infection is suspected during pregnancy. We therefore strongly recommend that specimens giving a positive result with a commercial assay should be sent to a reference laboratory.
The purpose of this work was to investigate the performance of commercially available kits for the detection of IgM class antibodies specific for $T$ gondii, without reference to their relative cost. Since the completion of this evaluation we understand that at least two manufacturers intend to modify their kits.

\section{References}

1 Remington JS, Miller MJ, Brownlee J. IgM antibodies in acute toxoplasmosis. II. Prevalence and significance in acquired cases. J Clin Med 1968;71:855-66.

2 Naot Y, Remington JS. An enzyme-linked immunosorbent assay for detection of IgM antibodies to Toxoplasma gondii, use for diagnosis of acute acquired toxoplasmosis. J Infect Dis 1980;142:757-66.

3 Payne RA, Joynson DHM, Balfour AH, et al. Public Health Laboratory Service enzyme linked immunosorbent assay for detecting Toxoplasma specific IgM antibody. J Clin Pathol 1987;40:276-81.

4 Fleck DG, Kwantes W. The laboratory diagnosis of toxoplasmosis. Public Health Laboratory Service, Monograph series 13. London: HMSO, 1980.

5 Herbrink P, van Loon AM, Rotmans JP, et al. Interlaboratory evaluation of indirect enzyme-linked immunosorbent assay, antibody capture enzyme-linked immunosorbent assay and immunoblotting for detection of immunoglobulin $\mathbf{M}$ antibodies to Toxoplasma gondii. J Clin Microbiol 1987;25:100-5.

Requests for reprints to: Dr D H M Joynson, Public Health Laboratory, Singleton Hospital, Sgeti, Swansea SA2 8QA, Wales. 